Sc Momčilo Đorovic, potpukovnik, dipl. inž. VP 4954 Danilovgrad

\section{SIMULATOR TEKUĆEG PRIJEMNOG SIGNALA RADARSKOG SENZORA PREPREKA ZA NISKOLETEĆE PLATFORME}

\author{
UDC: $629.735 .052: 621.396 .963$
}

Rezime:

$U$ radu je predložen matematički model simulatora tekućeg prijemnog signala radarskog senzora prepreka (RSP) za niskoleteće platforme (NLP). Odbirci tekućeg prijemnog signala nastaju sumiranjem anvelopa elementarnih signala svih elementarnih doprinosa po rezolucionim celijama. Zbog kretanja NLP i skaniranja snopa zračenja antene, odbirci tekućeg prijemnog signala izračunavaju se za svaki impuls predajnog signala. Vreme se eksplicitno uzima u obzir kroz računanje trenutnog prescka DMT i snopa zračenja antene, odnosno selekciju vidljivih elementarnih površina. Produkt simulacije su odbirci anvelope VF video-signala $u$ različitim trenucima $i$ odgovarajucim odmercima po rastojanju, koji sadrže sve relevantne podatke o: preprekama na trajektoriji leta NLP, parametrima RSP, i omogućavaju formiranje kompletne slike o sistemu u celini. Ovakav simulator smanjuje potrebu za eksperimentalnim merenjima reflektovanih signala od površine terena, što donosi znatne materijalne uštede.

Ključne reči: radarski senzor prepreka, niskoleteće platforme, matematički model, simulator prijemnog signala, odbirak tekućeg prijemnog signala.

\title{
COMPUTER SIMULATION MODEL OBSTACLE RADAR SENZORS FOR LOW-FLYING PLATFORMS
}

\section{Summary:}

A mathematical model simulation current receiving signal obstacle radar sensors for low-flying platforms in this paper is presented. Sample current receiving signal formed by reflection/scattering of electromagnetic vawes from all visual surfaces/scatters inside the resolutionary cells. Because of the moving of low-flying platform and antenna scanning, samples of the current receiving signal are determined for ever impulse of the current transmitting signal. Time is explicitly taken into account through the selection of the visual elementary surfaces/scatters inside the resolutionary cells. Product of this simulation are samples envelops of high-frequency, video signal in different moments and corresponding in distance samples, which contain all important about: obstacles on the fluent track of the flight of low-flying platform, parameters of the obstacle radar senzors, and they give a complete picture of the whole system. This kind of simulator decreases the need for experimental measurements of the clutter returns that are reflected from the surface and leands to big maretial saving.

Key words: obstacle radar sensor, low-flying platform, mathematical model, computer simulator received signal, sample of current receiving signal. 


\section{Simulacioni model radarskog senzora prepreka za niskoleteće platforme}

Fenomenološka razmatranja pokazala su da se formiranje odbiraka tekućeg prijemnog signala $\dot{u}_{\mathrm{pr}}\left(\mathrm{t}_{\mathrm{vm}}\right)$ vrši sumiranjem (1) parcijalnih signala $\dot{\mathrm{u}}_{\mathrm{s}}\left(\mathrm{t}_{\mathrm{vm}}\right)$ i šuma $\dot{\mathrm{u}}_{\mathrm{n}}\left(\mathrm{t}_{\mathrm{vm}}\right)$ :

$$
\dot{u}_{\mathrm{pr}}\left(\mathrm{t}_{\mathrm{vm}}\right)=\dot{\mathrm{u}}_{\mathrm{s}}\left(\mathrm{t}_{\mathrm{vm}}\right)+\dot{\mathrm{u}}_{\mathrm{n}}\left(\mathrm{t}_{\mathrm{vm}}\right)
$$

gde je:

$t_{v m}=v T_{i}+\tau_{m+1}$.

$\mathrm{U}$ svakom momentu vremena $t_{\mathrm{vm}}$ nastaje m odbiraka tekućeg prijemnog * signala, pri čemu u formiranju svakog od njih učestvuje $n$ elementarnih površina. Sve vidljive elementarne površine koje se nalaze $u$ osvetljenoj oblasti, formiraju $\mathrm{m}$ jedinstvenih raspršnih površina $\Delta S_{\mathrm{m}}$ - radarskih rezolucionih ćelija, dimenzija $\Delta r$ po dužini i $H_{m}$ po širini (4).

Trenutna vrednost m-tog odbirka (od m-te rezolucione ćelije), prijemnog signala $\dot{u}_{m}\left(t_{v m}\right)$, nastaje sumiranjem $n$ elementarnih signala $\dot{\mathrm{u}}_{\mathrm{mn}}\left(\mathrm{t}_{\mathrm{vm}}\right)$ raspršenih $u$ diskretnim momentima vremena $t_{v m}$. Broj rezolucionih ćelija je $\mathrm{m}=0,1,2, \ldots, \mathrm{N}_{\mathrm{r}-1} \mathrm{i}$ svaka od $\mathrm{njih}$ ima $\mathrm{n}=0,1,2, \ldots, \mathrm{N}_{\mathrm{m}}$ elementarnih površina/raspršivača. Raspored elementarnih površina $\mathrm{u}$ ravni $\mathrm{O}_{\mathrm{o}} \mathrm{X}_{\mathrm{z}} \mathrm{Y}_{\mathrm{z}} \mathrm{u}$ trenutku $\mathrm{t}=0 \quad(\mathrm{v}=0)$ prikazan je na slici 6 . Indeks $m$ je diskretna koordinata m-te rezolucione ćelije.

Dakle, važan je iznos odbiraka tekućeg prijemnog signala $\dot{\mathrm{u}}_{\mathrm{mn}}\left(\mathrm{t}_{\mathrm{vm}}\right) \mathrm{u}$ diskretnim trenucima vremena:

$$
\mathrm{t}_{\mathrm{vm}}=\mathrm{vT}_{\mathrm{i}}+\tau_{\mathrm{k}}+\left(\mathrm{m}+\mathrm{k}_{\mathrm{r}}\right) \cdot \Delta \tau ;
$$

$$
\tau_{k}=\sqrt{\left.\mathrm{x}_{\mathrm{o}}+\mathrm{h}_{\mathrm{o}}\right) / \mathrm{c}}
$$

gde je:

$\mathbf{x}_{\mathbf{0}}$ - početna koordinata posmatrane rezolucione ćelije (na slici $6 \mathrm{~m}=0$ );

$\Delta \tau$ - korak diskretizacije prijemnog signala, povezane sa korakom diskretizacije po daljini $\Delta_{\mathrm{r}}=$ $=\Delta \mathrm{r} / \mathrm{k}_{\mathrm{r}}$ relacijom $\Delta_{\mathrm{r}}=\Delta \tau \mathrm{c} /(2$. $\cdot \sin \varepsilon)$;

$\mathrm{k}_{\mathrm{r}}$ - koeficijent odmeravanja signala po daljini, koji predstavlja broj odmeraka signala od jedne rezolucione ćelije;

$\varepsilon \quad$ - ugao između ose snopa zračenja antene $\mathrm{i}$ ose $\mathrm{O}_{\mathrm{o}} \mathrm{Z}_{\mathrm{z}}$.

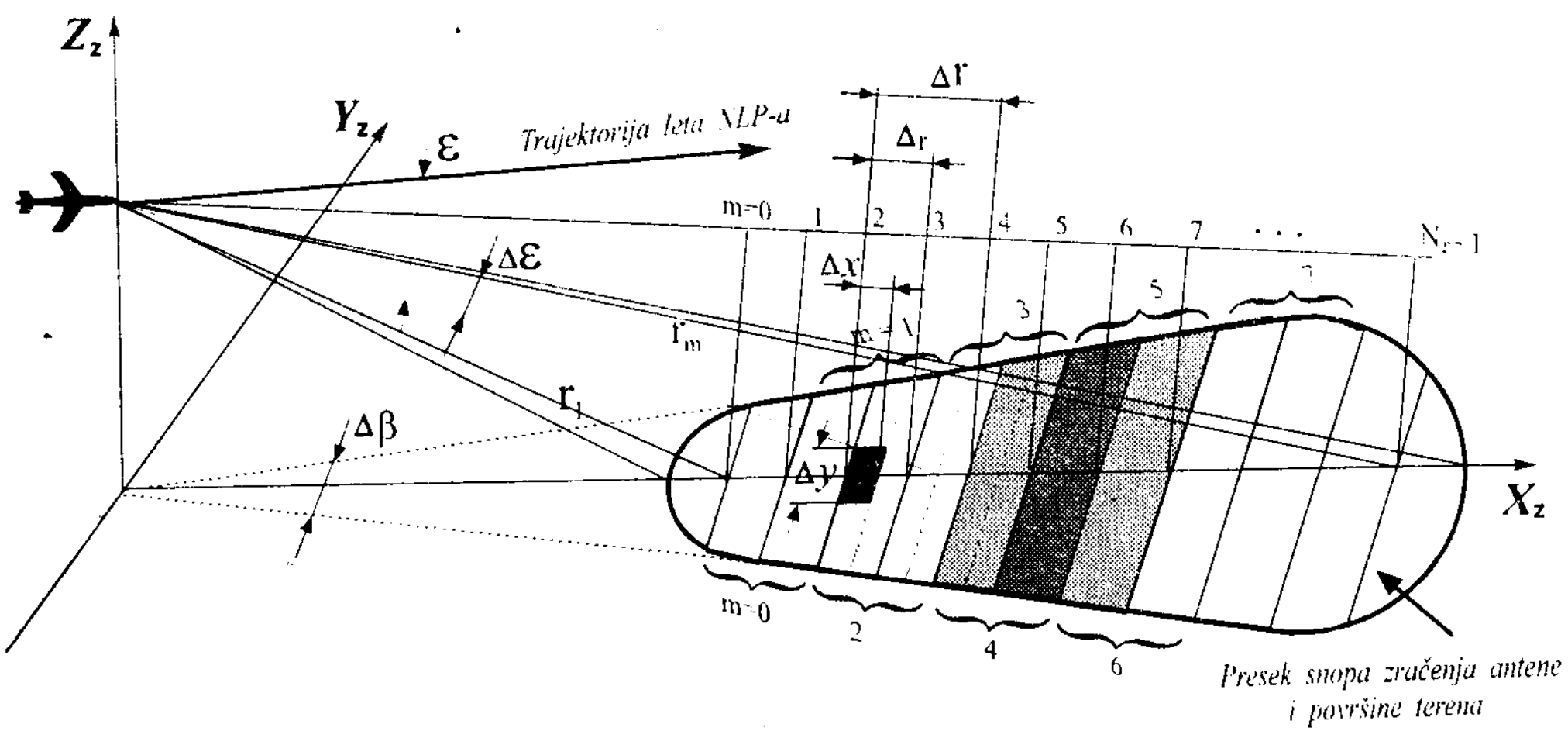

Sl. 6 - Presek snopa zračenja antene i površine terena $i$ odnos elementarnih površina $i$ rezolucionih celija 
U suštini, odbirci prijemnog signala po koordinati $\mathrm{x}$ i po kosoj daljini $r$ svode se na odmerke po vremenu. Razlika je $u$ tome što odbirci po koordinati $\mathrm{x}$ odgovaraju periodu ponavljanja predajnog impulsa i vezani su sa impulsnim radom RSP, a odbirci po kosoj daljini odgovaraju odmercima po vremenu unutar impulsnog perioda s korakom $\Delta \tau=1 / \mathrm{f}_{\mathrm{r}} \mathrm{i}$ vezani su za $\mathrm{A} / \mathrm{D}$ konverziju signala.

$\mathrm{Na}$ slici 6 prikazan je uzajamni položaj NLP i osvetljenog dela površine terena, koji je podeljen po daljini na rezolucione površine. $\mathrm{Na}$ njoj se vidi i veza broja rezolucionih ćelija $\mathrm{s}$ brojem odbiraka signala po daljini.

Ovde je:

$$
\begin{aligned}
& \mathrm{m}=\operatorname{int}\left\{\left(\mathrm{r}-\mathrm{r}_{1}\right) / \Delta_{\mathrm{r}}\right\}= \\
& =0,1,2, \ldots, \mathrm{N}_{\mathrm{r}}-1
\end{aligned}
$$

- redni broj odbirka prijemnog signala po daljini, a:

$$
\mathrm{N}_{\mathrm{r}}=\operatorname{int}\left\{\left(\mathrm{r}_{\mathrm{m}}-\mathrm{r}_{1}\right) / \Delta_{\mathrm{r}}\right\}+1
$$

- ukupan broj odbiraka prijemnog signala po daljini.

Ilustracija na slici 6 pokazuje slučaj kada se od svake rezolucione ćelije uzimaju po dva odbirka signala $\left(\mathrm{k}_{\mathrm{r}}=2\right)$. Susedne površine se prekrivaju po pola, pa proizilazi da svaka elementarna površina/raspršivač ima svoj udeo i učestvuje komponentama elementarnog signala $u$ formiranju dva susedna odbirka signala po daljini.

$\mathrm{U}$ diskretnim momentima vremena $t_{v m}$ dolazi do raspršenja od $N_{r}-1$ rezolucionih ćelija $s$ centralnim elementarnim površinama $A_{m}, A_{m+1}, \ldots$ raspoređenih duž ose $\mathrm{O}_{\mathrm{o}} \mathrm{X}_{\mathrm{z}}$. Na primer, za elementarnu površinu $s$ koordinatom $\mathrm{m}=0 \quad\left(\mathrm{za} \mathrm{k}_{\mathrm{r}}=2, \mathrm{v}=0\right), \quad \dot{\mathrm{u}}_{\mathrm{o}}=\left(\mathrm{t}_{\mathrm{oo}}\right)$ predstavlja vrednost odbirka tekućeg prijemnog signala $u$ trenutku $t_{o o}=\tau_{k}+2$.

- $\Delta \tau$, koji odgovara početku prijema signala, raspršenog od elementarnih površina $\mathrm{s}$ diskretnom koordinatom $\mathrm{x}=0$.
$\mathrm{Na}$ osnovu navedenog, serija diskretnih odbiraka prijemnog signala $\dot{u}_{p r}\left(t_{v m}\right)$ može se izraziti u obliku diskretnog signala kao funkcija celobrojnih argumenata $v, m$ i $n$ :

$$
\begin{aligned}
& \dot{\mathrm{u}}_{\mathrm{pr}}[\mathrm{v}, \mathrm{m}]=\sum_{\mathrm{m}=0} \sum_{\mathrm{n}=1}^{\mathrm{N}-1 \mathrm{u}_{\mathrm{n}(\mathrm{m}+1)}}\left[\mathrm{vT}_{\mathrm{i}}+\right. \\
& \left.+\tau_{\mathrm{k}}+\left(\mathrm{m}+\mathrm{k}_{\mathrm{r}}\right) \cdot \Delta \tau\right] \\
& \mathrm{v}=0, \pm 1, \pm 2, \ldots
\end{aligned}
$$

gde je:

$\mathrm{N}_{\mathrm{m}}$ - broj osvetljenih $\mathrm{i}$ vidljivih elementarnih površina $\mathrm{u}$ m-toj rezolucionoj ćeliji, koji se proračunava za svaki period $T_{i}$, jer se vremenom stajna tačka NLP, kao i položaj snopa zračenja antene, zbog skaniranja, menja.

Vidljive elementarne površine $u$ rezolucionim ćelijama $m=4$ i 5 na slici 6 šrafirane su različitom gustinom. Posmatra se prijemni signal u nultom periodu ponavljanja predajnog impulsa $(v=0)$ i od svake rezolucione ćelije uzimaju se dva odbirka prijemnog signala $\left(\mathrm{k}_{\mathrm{r}}=2\right)$.

$\mathrm{Na}$ osnovu izraza (11) do (14) i (23) diskretni odbirci $\dot{u}_{\mathrm{mn}}\left(\mathrm{t}_{\mathrm{vm}}\right)$ mogu se napisati kao:

$$
\begin{aligned}
& \dot{\mathrm{u}}_{\mathrm{mn}}\left(\mathrm{t}_{\mathrm{vm}}\right)=\dot{\mathrm{U}}_{\mathrm{mn}}\left(\mathrm{t}_{\mathrm{vm}}\right) \cdot \dot{\eta}_{\mathrm{mn}}\left(\mathrm{t}_{\mathrm{vm}}\right) \\
& \dot{\mathrm{U}}_{\mathrm{mn}}\left(\mathrm{t}_{\mathrm{vm}}\right)=\mathrm{U} \cdot \sigma_{\mathrm{mn}} \cdot \mathrm{G}_{\mathrm{mn}}^{2}\left(\mathrm{t}_{\mathrm{vm}}\right) \cdot \\
& \cdot \exp \left[\mathrm{j} \varphi_{\mathrm{mn}}\left(\mathrm{t}_{\mathrm{vm}}\right)\right] \\
& \mathrm{U}=v^{\prime}\left(\mathrm{P}_{\mathrm{i}} \cdot \mathrm{G}_{\mathrm{o}}^{2} \cdot \lambda^{2} \cdot \mathrm{a}_{\mathrm{r}}\right) / 4 \pi^{3} \\
& \varphi_{\mathrm{nm}}\left(\mathrm{t}_{\mathrm{vm}}\right)=\mathrm{t}_{\mathrm{vm}} \cdot \omega_{\mathrm{vm}}=-4 \cdot \pi \\
& \cdot \mathrm{V}_{\mathrm{l}}^{2}\left[\mathrm{t}_{\mathrm{vm}}+\left(\mathrm{n}-\mathrm{N}_{\mathrm{v}}\right) \cdot \Delta \mathrm{r} / \mathrm{V}_{1}\right]^{2} / \lambda \\
& \mathrm{N}_{\mathrm{v}}=\operatorname{int}\left\{\left[\mathrm{v} \cdot \mathrm{T}_{\mathrm{i}} \cdot \mathrm{V}_{\mathrm{l}} / \Delta \mathrm{r}\right]+\operatorname{signv}\right\},
\end{aligned}
$$

gde je:

$\mathrm{N}_{\mathrm{v}}$

- celobrojana diskretna promenljiva koja karakteriše skaniranje snopa zračenja ante- 
ne po koordinati $\mathrm{x} u$ sled kretanja NLP;

$\dot{\eta}_{\mathrm{mn}}\left(\mathrm{t}_{\mathrm{vm}}\right)$ - odbirak slučajnog normiranog procesa $\mathbf{s}$ jednačinom disperzije (16), uzimajući u obzir slučajnu fazu prijemnog signala;

$\mathrm{G}_{\mathrm{mn}}(\mathrm{t})$ - iznos normiranog snopa zračenja antene $u$ pravcu n-te elementarne površine m-te rezolucione ćelije $u$ trenutku t;

$\sigma_{\mathrm{mn}}=\Delta \mathrm{s}$ - efektivna radarska po- $\sigma_{\mathrm{x}}(\mathrm{x}, \mathrm{y}, \alpha, \beta, \mathbf{P}) \quad$ vršina n-te elementarne površine, gde je $\Delta s$ $=\Delta \mathrm{x} \cdot \Delta \mathrm{y}, \mathrm{a} \sigma_{\mathrm{x}}(\mathrm{x}, \mathrm{y}, \alpha, \beta, \mathrm{P})$ - specifična radarska površina n-te elementarne površine, koja zavisi od koordinata $(\mathrm{x}, \mathrm{y})$, upadnih uglova elektromagnetskih talasa $(\alpha, \beta)$ i vrste vegetacije/raspršivača na njoj (P);

$\varphi_{\mathrm{mn}}(\mathrm{t}) \quad$ - funkcija promene faze reflektovanog signala od elementarne površine $A_{n m}$, ne uzimajući u obzir $\Phi_{m n}(t)$;

$\mathrm{P}_{\mathrm{i}} \quad$ - impulsna snaga predajnog signala;

$a_{r}$

- koeficijent slabljenja signala na trasi prostiranja. Indeksi $\mathrm{n}$ i m odnose se na n-tu elementarnu površinu i m-te rezolucione ćelije $\left(\Delta S_{\mathrm{m}}\right)$.

Kako se funkcije $\dot{\eta}_{m n}\left(t_{v m}\right)$ i $G_{m n}(t)$ sasvim malo menjaju za vreme kašnjènja signala $\tau_{\mathrm{m}}=\tau_{\mathrm{k}}+\left(\mathrm{m}+\mathrm{k}_{\mathrm{r}}\right) \cdot \Delta \tau$, mogu se napisati $u$ obliku:

$$
\begin{aligned}
& \dot{\eta}_{\mathrm{mn}}\left(\mathrm{t}_{\mathrm{vm}}\right) \approx \eta_{\mathrm{mn}}\left(\mathrm{vT}_{\mathrm{i}}\right) \\
& \mathrm{G}_{\mathrm{mn}}\left(\mathrm{t}_{\mathrm{vm}}\right) \approx \mathrm{G}_{\mathrm{mn}}\left(\mathrm{vT}_{\mathrm{i}}\right)
\end{aligned}
$$

Koristeći izraze (41 do 46) i (37) tekući prijemni signal (36) može se izraziti u obliku kvadraturnih komponenata $u$ funkciji diskretnih argumenata $\mathrm{v}, \mathrm{n}$ i m:

$$
\begin{aligned}
& \dot{\mathrm{u}}_{\mathrm{pr}}[\mathrm{v}, \mathrm{m}]=\dot{\mathrm{u}}_{\mathrm{prr}}[\mathrm{v}, \mathrm{m}]+\mathrm{ju} \dot{\mathrm{pri}}[\mathrm{v}, \mathrm{m}] \\
& \dot{\mathrm{u}}_{\mathrm{prr}}[\mathrm{v}, \mathrm{m}]=\mathrm{U}_{\mu=0}^{\mathrm{Nr}} \sum_{\mathrm{n}=1}^{1 \mathrm{Nm}} \sqrt{\sigma_{\mathrm{mn}}} \cdot \mathrm{G}_{\mathrm{mn}}[\mathrm{v}] \\
& \cdot\left\{\xi_{\mathrm{n}(\mathrm{m}+\mu) \mathrm{r}}[\mathrm{v}] \cdot \cos \varphi_{\mathrm{mn}}[\mathrm{v}, \mathrm{m}]-\right. \\
& \left.-\xi_{\mathrm{n}(\mathrm{m}+\mu) \mathrm{i}}[\mathrm{v}] \cdot \sin \varphi_{\mathrm{mn}}[\mathrm{v}, \mathrm{m}]\right\} \\
& \dot{\mathrm{u}}_{\mathrm{pri}}[\mathrm{v}, \mathrm{m}]=\mathrm{U} \sum_{\mu=0}^{\mathrm{Nr}} \sum_{\mathrm{n}=1}^{1 \mathrm{Nm}} \sqrt{\sigma_{\mathrm{mn}}} \cdot \mathrm{G}_{\mathrm{mn}}[\mathrm{v}] \\
& \cdot\left\{\xi_{\mathrm{n}(\mathrm{m}+\mu) \mathrm{i}}[\mathrm{v}] \cdot \cos \varphi_{\mathrm{mn}}[\mathrm{v}, \mathrm{m}]-\right. \\
& \left.-\xi_{\mathrm{n}(\mathrm{m}+\mu) \mathrm{r}}[\mathrm{v}] \cdot \sin \varphi_{\mathrm{mn}}[\mathrm{v}, \mathrm{m}]\right\}
\end{aligned}
$$

gde je:

$\begin{aligned} \xi_{\mathrm{nmr}}[\mathrm{v}] \mathbf{i}_{\mathrm{nmi}}[\mathrm{v}]-\mathrm{F} & \text { realna i imaginarna } \\ \text { komponenta odbirka } & \text { slučanjog procesa } \xi_{\text {nm }} \\ & {[\mathrm{v}] . }\end{aligned}$

\section{Algoritam simulacionog modela}

Osnovu algoritma za simulaciju diskretnih odbiraka tekućeg prijemnog signala, raspršenog od površine terena, čine izrazi (15) i (16). Polazi se od nalaženja preseka snopa zračenja antene i elektrodinamičkog DMT, odnosno selekcije vidljivih elementarnih površina i određivanja upadnih uglova elektromagnetskih talasa na njih. Zatim se sve vidljive elementarne površine grupišu po rezolucionim ćelijama za svaki impuls predajnog signala. Odmerak tekućeg prijemnog signala nastaje sumiranjem elementarnih signala reflektovanih/raspršenih od vidljivih elementarnih površina $u$ nutar rezolucione ćelije.

Algoritam je razvijen za simulaciju odbiraka tekućeg prijemnog signala RSP u modu automatskog praćenja terena. Malim promenama on može da posluži i za simulaciju odbiraka teku- 
ćeg prijemnog signala RSP $\mathbf{u}$ modu ručnog izbegavanja prepreka. Na strukturnoj šemi algoritma, prikazanoj na slici 7, to nije naznačeno. Razlika je samo u bloku (potprogramu) koji simulira skaniranje snopa zračenja antene [9], i to $\mathrm{u}$ : modu automatskog praćenja terena snop zračenja antene skanira po elevaciji u granicama $\left(\varepsilon_{d}\right.$, $\varepsilon_{g}$ ) oko horizontalnog pravca leta $\varepsilon_{o}$, dok u modu ručnog izbegavanja prepreka snop zračenja antene skanira po azimutu $\mathrm{u}$ sektoru $\mathrm{u}$ odnosu na pravac leta $\beta$.

Algoritam je razvijen uz već navedena ograničenja o trajektoriji kretanja NLP, tehničkim karakteristikama RSP, osobinama elektrodinamičkog DMT, i za predajni impulsni signal s kompleksnom anvelopom oblika (6).

$\mathrm{Na}$ samom početku, odmah iza starta programa (blok 1), iz datoteke početnih parametara koja je ranije kreirana i napunjena, učitavaju se podaci (blok 2), koji karakterišu:

- elementarne površine DMT: $\Delta x$, $\Delta y, x, y, h(x, y), \alpha, \beta, P$;

- kretanje NLP: brzina $\left(\vec{V}_{1}\right)$ i relativna visina $\left(h_{0}\right)$;

- snop zračenja antene: širina $(\Delta \varepsilon, \Delta \beta)$, početni položaj snopa $\left(\varepsilon_{0}, \beta_{o}\right)$, sektor i brzina skaniranja.

Izborom dela elektrodinamičkog DMT (blok 3), iznad kojeg NLP leti, iz datoteke se preuzimaju osnovni podaci modela: $\Delta x, \Delta y, x_{\max }, y_{\max }$. Izbor željene trajektorije leta NLP (blok 4), vrši se zadavanjem početne $\left(\mathrm{x}_{\mathrm{ol}}, \mathrm{y}_{\mathrm{ol}}\right)$ i $\mathrm{kraj}$ nje $\left(\mathrm{x}_{\mathrm{kl}}, \mathrm{y}_{\mathrm{kl}}\right)$ tačke trajektorije.

Simulacioni proces počinje postavljanjem generatora vremena na nulu (blok 5). Pošto $u$ prvom ciklusu nema vremenskih pomaka $(\mathrm{v}=0)$ položaj NLP (blok 6) i snopa zračenja antene (blok 7), bez obzira na mod izbegavanja prepreke, ostaje nepromenjen.

$\mathrm{Na}$ osnovu pravca snopa zračenja antene $\left(\varepsilon_{0}, \beta_{0}\right)$, njegove širine na nivou pola snage $(\Delta \varepsilon, \Delta \beta)$, izdvajaju se vidljive elementarne površine terena (blok
8). Istovremeno se proračunavaju upadni uglovi elektromagnetskih talasa na svaku elementarnu površinu i vrši njihovo svrstavanje u odgovarajuće rezolucione ćelije. Naravno, pre toga se pomoću izraza (38) i (39) određuju granice rezolucionih ćelija, njihov ukupan i redni broj m (blok 9). Najbliža vidljiva elementarna površina svrstava se $\mathrm{u}$ prvu rezolucionu ćeliju $(\mathrm{m}=0)$. Istovremeno, određuje se i ukupan broj vidljivih elementarnih površina $u$ svakoj rezolucionoj ćeliji $n$. Vidljive elementarne ćelije grupišu se po rezolucionim ćelijama, na ovom nivou, tako što se pamte njihove adrese i upadni uglovi.

Kvadraturne komponente tekućeg prijemnog signala za prvu elementarnu površinu $(n=1)$ prve rezolucione ćelije $(\mathrm{m}=1)$ izračunavaju se pomoću izraza (40 do 44) (blokovi 10 i 11). Pri tome, za svaku vidljivu elementarnu površinu, koja se nalazi u m-toj rezolucionoj ćeliji, na osnovu adrese, dolazi se do njihovih podataka $(x, y, h$, $\alpha, \beta, P)$. Na osnovu njih prvo se izračuna daljina do elementarne površine, zatim vrednosti $\varphi_{n m}\left(t_{v m}\right), G_{m n}\left(v T_{i}\right)$, generišu slučajni brojevi $\xi_{\text {nmr }}[v]$ i $\xi_{\text {nmi }}[v]$ $s$ proračunatim doprinosom radarske površine $\sigma_{\mathrm{nm}}$. Sumiranje se obavlja na osnovu izraza (47) po indeksu n (blok 12 i 13). Ova procedura se ponavlja $\mathrm{N}_{\mathrm{r}}-1$ puta (za sve rezolucione celije intervale daljine). Na kraju procedure dobijaju se kvadraturne komponente tekućeg prijemnog signala $\mathrm{u} v$ periodu. Dobijeni odbirci spremaju se $u$ memoriju računara (blok 16).

Nakon $\mathrm{N}_{\mathrm{m}} \cdot \mathrm{N}_{\mathrm{r}}-1$ ciklusa izvršavanja algoritma dobijaju se odbirci kvadraturnih komponenata tekućeg prijemnog signala $\dot{u}_{\mathrm{prr}}[\mathrm{v}, \mathrm{m}] \mathrm{i} \dot{\mathrm{u}}_{\mathrm{pri}}[\mathrm{v}, \mathrm{m}]$ za vremenski trenutak $v \mathrm{u}$ intervalu simulacije RSP. Dobijene kvadraturne komponente formiraju skupove digitalnih podataka, koji se normiraju (blok 21) radi njihovog dovođenja u vezu s dinamikom procesa koji se simulira. 


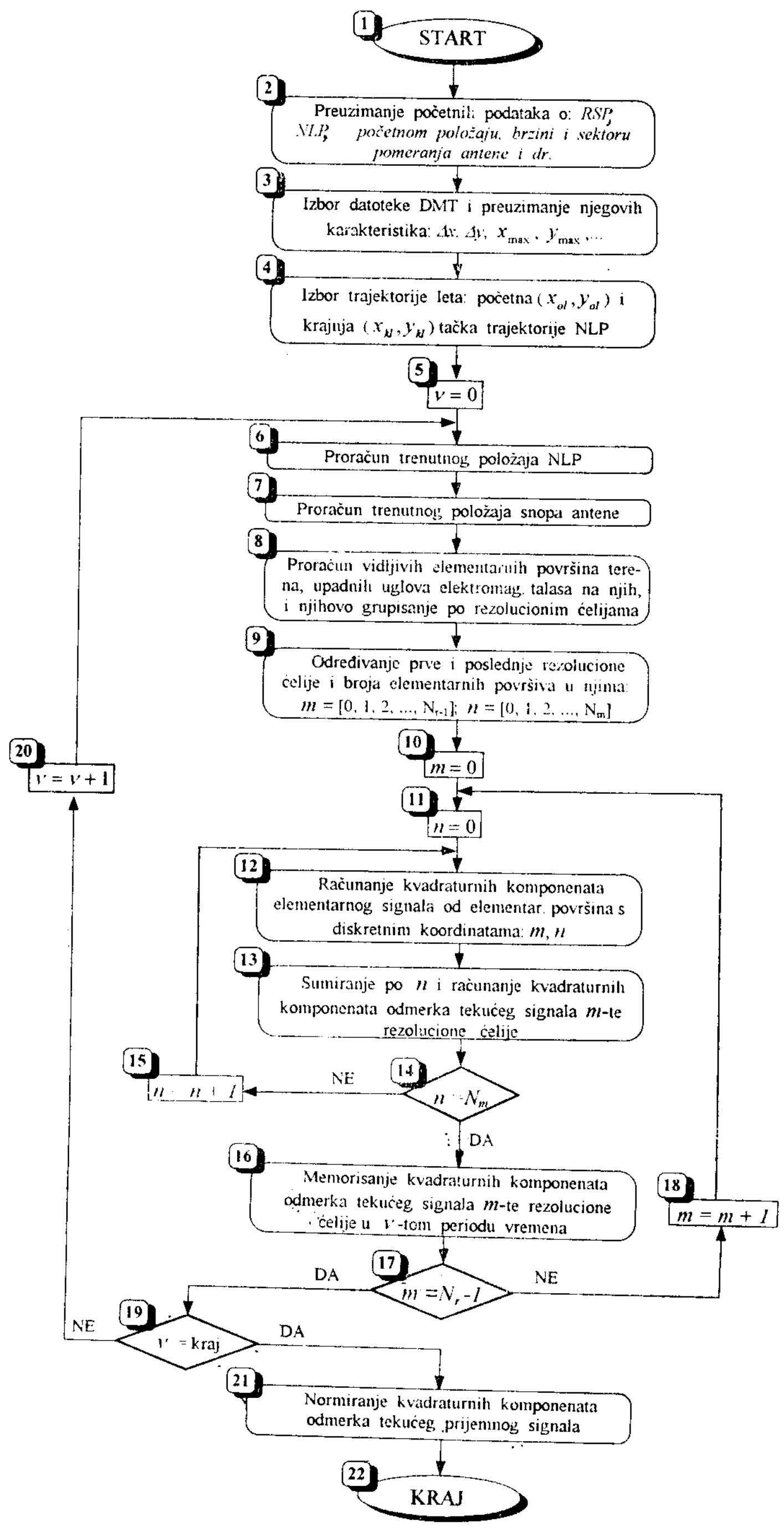

Sl. 7 - Strukturna šema algoritma simulacionog modela tekućeg prijemnog signala 


\section{Princip selekcije vidljivih elementarnih površina}

Ključna operacija $u$ algoritmu, prikazanom na slici 7 , jeste selekcija vidljivih elementarnih površina. Program funkcioniše po algoritmu ilustrovanom na slici 8.

Sličan problem rešavan je $\mathbf{u}[10]$ za stacionaran osmatrački radar. Međutim, program koji je razvijen za ovu namenu originalan je s obzirom na to da se radi o drugačijem snopu zračenja antene i da je RSP na NLP. Kriterijum vidljivosti je isti - kriterijum maksimalnog tangensa.

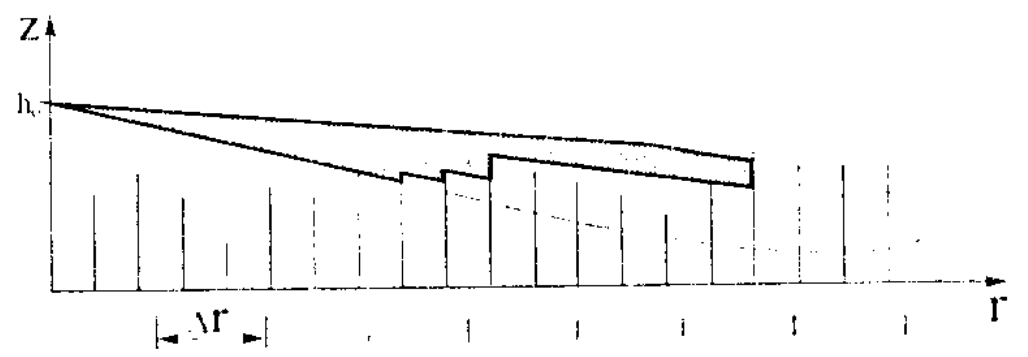

a)

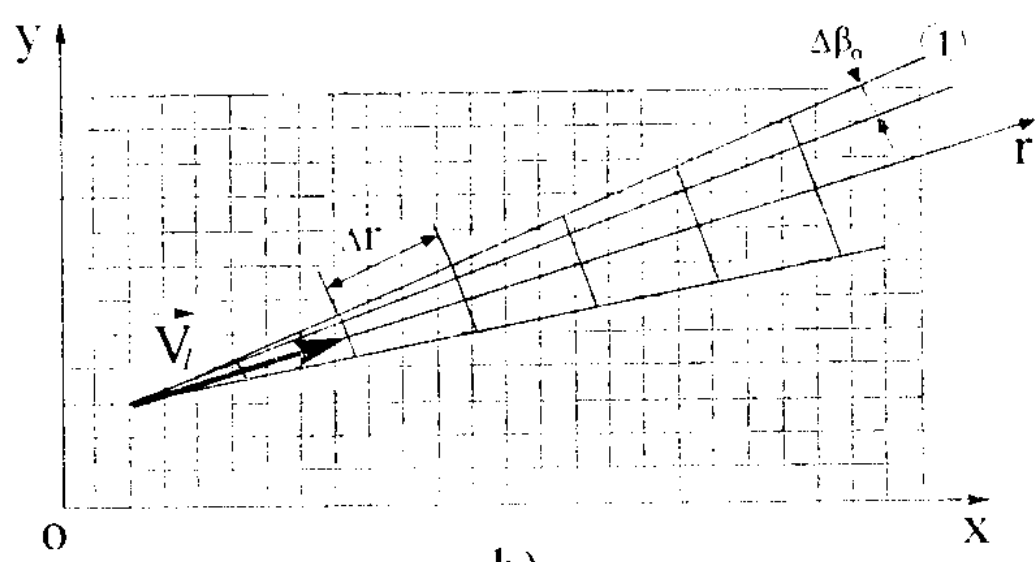

b)

Sl. $\delta$ - Izdvajanje vidljivih elementarnih površina iz stajne tačke RSP:

a) duž pravca leta $r$; b) $u$ horizontalnoj ravni terena $x \mathrm{Oy}$

Selekcija vidljivih elementarnih signala obavlja se tako što se ispituje vidljivost svake elementarne površine po azimutalnom pravcu $\left(\beta_{\mathrm{o}}-\Delta \beta / 2\right)$. $\mathrm{S}$ obzirom na nominalnu visinu leta NLP od $\mathrm{h}_{\mathrm{o}} \approx 100 \mathrm{~m}$, ispitivanje vidljivosti elementarnih površina počinje od te daljine. Dakle, na tom pravcu, na daljini trenutne relativne visine, pronalazi se najbliža elementarna površina. Iz dimenzija snopa zračenja antene izra- čunavaju se vrednosti donje $i$ gornje visine $h_{i 1} i h_{i 2}$ na toj lokaciji, kao što je to prikazano na slici 9.

Elementarna površina je vidljiva ako su zadovoljeni sledeći uslovi:

- ako je osvetljena, tj. upada u snop zračenja antene $h_{i}>h_{i 1}$,

- ako ima veći tangens upadnog ugla od elementarne površine neposredno ispred nje.

$\mathrm{Na}$ slici 9 prikazan je primer kada je elementarna površina: 1 - nevidljiva zbog toga što se ne nalazi u snopu zračenja antene (nije ispunjen prvi uslov), 2 - vidljiva, 3 i 5 - nevidljive, jer se nalaze u senci (nije zadovoljen drugi uslov) i 4 - vidljiva. Kada se zadovolji uslov $h_{i 1}>h_{i 2}$ prestaje ispitivanje vidljivosti elementarnih površina na tom pravcu. Uzima se sledeći pravac $\left(\beta_{\mathrm{o}}-\Delta \beta / 2+\Delta \beta_{\mathrm{p}}\right)$, pomaknut za $\Delta \beta_{\mathrm{p}}$ udesno. $\Delta \beta_{\mathrm{p}}$ se određuje tako da sve elementarne površine na krajnjim udaljenostima (u modelu je za krajnje daljine uzeta vrednost od $5 \mathrm{~km}$ ), budu obuhvaćene ispitivanjem. Sve vidljive tačke svrstavaju se u odgovarajuće rezolucione ćelije, po kriterijumu udaljenosti od RSP.

Zbog veće gustine elementarnih površina na bližim daljinama, vidljivost jedne iste elementarne površine ispituje se više puta. Zato se pre uvr-

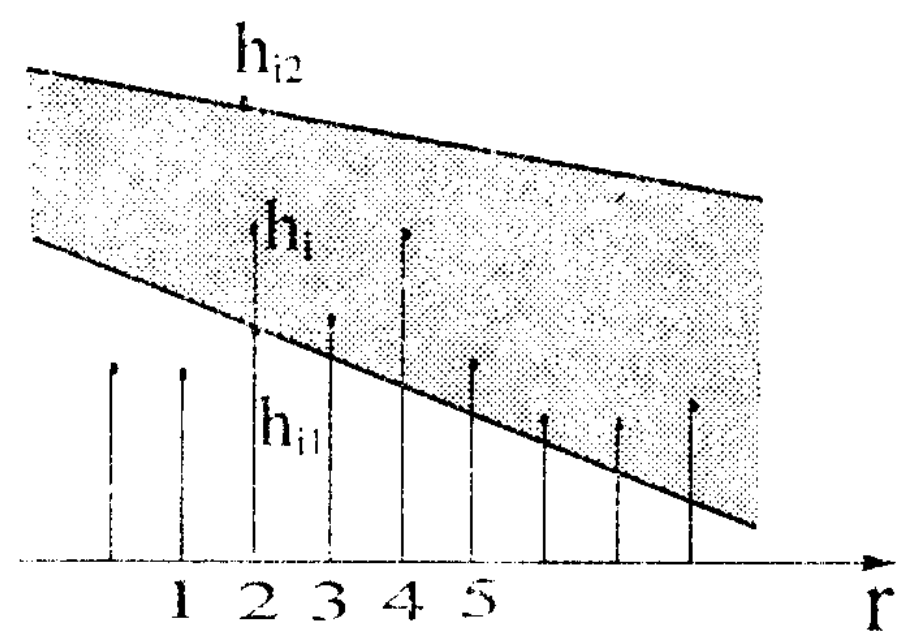

Sl. 9 - Princip selekcije vidljivih elementarnih površina na jednom pravcu posmatranja 
štavanja elementarne površine u odgovarajuću rezolucionu ćeliju uvek ispituje da li je ona u nju već uvrštena. Ukoliko jeste, prelazi se na ispitivanje vidljivosti sledeće tačke na istom pravcu.

\section{Zaključak}

Zahvaljujući razvoju matematičkih modela, koji opisuju fenomene iz oblasti radarske teorije, $\mathrm{i}$ brzom razvoju računara opšte namene metode matematičkog modelovanja i simulacije na računaru postale su dominantne $u$ oblasti analiza i sinteza RS [1 do 7].

$\mathrm{U}$ radu je opisan simulacioni model RSP za NLP koji je zasnovan na mehanizmu njegovog funkcionisanja. Kako je odbirak tekućeg prijemnog signala RSP na NLP određen trenutnim uzajamnim položajem snopa zračenja antene $\mathrm{i}$ elementarnih raspršivača/površina terena, to se u svakom momentu vremena $t_{\mathrm{vm}}$ formira $m$ odbiraka tekućeg prijemnog signala, pri čemu u formiranju svakog od njih učestvuje $\mathrm{n}$ elementarnih površina. Sve vidljive elementarne površine iz osvetljene oblasti formiraju $\mathrm{m}$ jedinstvenih raspršnih površina $\Delta S_{m}$ - radarskih rezolucionih ćelija. Vrednosti elementarnih signala dobijaju se na osnovu podataka sadržanih $u$ elektrodinamičkom

Literatura:

[1] Blake, I. V.: Fortran computer program to calculate range of a pulse radar, NRL Report - 7448, August 28, 1972.

[2] Mitchell, R. L.: Radar signal simulations, Artech House, Dedharm, 1976.

[3] Леонов, А. И.: Моделирование в радиолокацији, Совјетскоје радио, Москва, 1979.

[4] Suresh-Babu, B. N.: Simulation of correlated clutter environment, Conference Procedings, Computer Simulations, Montreal, Quebec, July 1987, pp 246-250.

[5] Cynemen, J. J.: Radar computer simulation arhitecture \& organization, Conference Procedings, Computer Simulations, Montreal, Quebec, July 1987, pp 241-245.

[6] Potter, K. E.: Experimental desing study of an airborne interferometer for terrain avoidance, Conference Procedings, Computer Simulations, Montreal, Quebec, July 1987, pp $508-512$.
DMT - bazi podataka o raspršnim karakteristikama pojedinih pokrivača i proračunatih upadnih uglova.

Simulator odbirka tekućeg prijemnog signala realizovan je implementacijom matematičkog modela RSP za NLP i elektrodinamičkog DMT na računaru. Rad počinje preuzimanjem početnih podataka o RSP, NLP, izborom datoteke DMT i trajektorije leta NLP. $\mathrm{Na}$ osnovu trenutnog položaja NLP i snopa zračenja antene, određuje se njegov presek sa elektrodinamičkim DMT, odnosno vrši selekcija vidljivih elementarnih površina, koje se grupišu u $\mathrm{m}$ jedinstvenih raspršnih površina $\Delta \mathrm{S}_{\mathrm{m}}$ - radarskih rezolucionih ćelija. Dakle, u svakom momentu vremena $t_{\mathrm{vm}}$ nastaje $\mathrm{m}$ odbiraka tekućeg prijemnog signala, pri čemu u formiranju svakog od njih učestvuje $n$ elementarnih raspršivača/površina. Kvadraturne komponente elementarnih signala dobijaju se na osnovu podataka sadržanih u elektrodinamičkom DMT, bazi podataka o raspršnim karakteristikama pojedinih raspršivača/pokrivača i izračunatih upadnih uglova elektromagnetskih talasa. Kvadraturne komponente svakog od m odbiraka dobijaju se sumiranjem n kvadraturnih komponenata elementarnih signala koji ga formiraju onoliko puta koliko se puta ponavlja i procedura izračunavanja elementarnih signala.

[7] Kostić, A., Kovačević, B., Radosavljević, Lj., Stanković, S., Živojinović, V.: Funkcionalna simulacija radara, Naučno-tehnički pregled, №7-8, 1991, str. 49-55.

[8] Rigel, M. B.: An advanced computer calculation of graund clutter in airborne pulse-doppler radar, Procedings of the IEEE NAECON-77, Dayton, 1981, pp 921-928.

[9] Đorović, M.: Digitalni model terena za modeliranje radarskih senzora prepreka na niskoletećim platformama, Naučno-tehnički pregled, No7-8, 1991, str. 56-63.

[10] Salapura, V.: Analiza dijagrama pokrića radara na temelju digitalnog modela reljefa, NIR zadatak 516F, CVTS KoV, Zagreb, 1986. 